\title{
High-precision measurements of nitrous oxide and methane in air with cavity ring-down spectroscopy at $\mathbf{7 . 6} \boldsymbol{\mu m}$
}

\author{
Jing Tang, Bincheng Li, and Jing Wang \\ School of Optoelectronic Science and Engineering, University of Electronic Science \\ and Technology of China, Chengdu 610054, China
}

Correspondence: Bincheng Li (bcli@uestc.edu.cn)

Received: 29 October 2018 - Discussion started: 15 November 2018

Revised: 8 April 2019 - Accepted: 19 April 2019 - Published: 20 May 2019

\begin{abstract}
A high-sensitivity methane $\left(\mathrm{CH}_{4}\right)$ and nitrous oxide $\left(\mathrm{N}_{2} \mathrm{O}\right)$ sensor based on mid-infrared continuous-wave (CW) cavity ring-down spectroscopy (CRDS) techniques was developed for environmental and biomedical tracegas measurements. A tunable external-cavity mode-hop-free (EC-MHF) quantum cascade laser (QCL) operating at 7.4 to $7.8 \mu \mathrm{m}$ was used as the light source. The effect of temperature fluctuation on the measurement sensitivity of the CRDS experimental setup was analyzed and corrected, and a sensitivity limit of absorption coefficient measurement of $7.2 \times 10^{-10} \mathrm{~cm}^{-1}$ was achieved at $1330.50 \mathrm{~cm}^{-1}$ with an average of 139 measurements or $21 \mathrm{~s}$ averaging time and further improved to $2.3 \times 10^{-10} \mathrm{~cm}^{-1}$ with an average of 3460 measurements, or $519 \mathrm{~s}$ averaging time. For the targeted $\mathrm{CH}_{4}$ and $\mathrm{N}_{2} \mathrm{O}$, absorption lines located at 1298.60 and $1327.07 \mathrm{~cm}^{-1}$ with temperature effect correction detection limits of 13 and 11 pptv were experimentally achieved with 10.4 and $10.2 \mathrm{~s}$ averaging times and could be further improved to 5 and 9 pptv with 482.5 and $311 \mathrm{~s}$ averaging times, respectively. Four spectral bands (1298.4 to $1298.9 \mathrm{~cm}^{-1}$, 1310.1 to $1312.3 \mathrm{~cm}^{-1}, 1326.5$ to $1328 \mathrm{~cm}^{-1}$, and 1331.5 to $1333 \mathrm{~cm}^{-1}$ ) in the spectral range from 1295 to $1335 \mathrm{~cm}^{-1}$ were selected for the separate and simultaneous measurements of $\mathrm{CH}_{4}$ and $\mathrm{N}_{2} \mathrm{O}$ under normal atmospheric pressure, and all were in good agreements. The concentrations of $\mathrm{CH}_{4}$ and $\mathrm{N}_{2} \mathrm{O}$ of atmospheric air collected at different locations and of exhaled breath were measured and analyzed. Continuous measurements of $\mathrm{CH}_{4}$ and $\mathrm{N}_{2} \mathrm{O}$ concentrations of indoor laboratory air over $45 \mathrm{~h}$ were also taken. It was found that anaerobic bacteria in the water and soil of wetlands might significantly increase the $\mathrm{CH}_{4}$ concentration in the air. The measured $\mathrm{N}_{2} \mathrm{O}$ concentration in the central city area was
\end{abstract}

somewhat lower than the reported normal level in open air. Our results demonstrated the temporal and spatial variations of $\mathrm{CH}_{4}$ and $\mathrm{N}_{2} \mathrm{O}$ in the air.

\section{Introduction}

Methane $\left(\mathrm{CH}_{4}\right)$ and nitrous oxide $\left(\mathrm{N}_{2} \mathrm{O}\right)$ are two of the most important atmospheric greenhouse gases, the concentrations of which have been increasing continuously since pre-industrial time (Hartmann et al., 2013). Moreover, the global warming potential (GWP) of $\mathrm{CH}_{4}$ is about 25 times greater than that of carbon dioxide $\left(\mathrm{CO}_{2}\right)$ (Boucher et al., 2009), while the GWP of $\mathrm{N}_{2} \mathrm{O}$ is 300 times (Rapson and Dacres, 2014) greater than that of $\mathrm{CO}_{2}$. Apart from natural processes, the spatial distributions of both, to a great extent, depend on human activities, such as agricultural practices (Mosier et al., 1998), organic waste, and industrial activities. Even small changes in concentrations of $\mathrm{CH}_{4}$ and $\mathrm{N}_{2} \mathrm{O}$ in atmosphere have a great influence on the natural environment. Therefore, the highly sensitive and precise measurements of $\mathrm{CH}_{4}$ and $\mathrm{N}_{2} \mathrm{O}$ concentrations in atmospheric air are essential to environmental monitoring and controlling greenhouse gases. For sensitive $\mathrm{CH}_{4}$ and $\mathrm{N}_{2} \mathrm{O}$ detection in the air a spectral range around $7.6 \mu \mathrm{m}$ is one of the most suitable, as (1) in the wave number range from 1290 to $1350 \mathrm{~cm}^{-1}, \mathrm{CH}_{4}$ and $\mathrm{N}_{2} \mathrm{O}$ have the second strongest fundamental vibration bands, and (2) in this spectral range there are minimum interference absorption lines from other gases (carbon dioxide $\left(\mathrm{CO}_{2}\right)$, carbon monoxide $(\mathrm{CO})$, ammonia $\left(\mathrm{NH}_{3}\right)$, nitrogen monoxide (NO), etc.) in the air except water vapor, which can be easily eliminated by drying the gas under test. 
Cavity enhanced absorption techniques, such as cavity ring-down spectroscopy (CRDS) (Banik et al., 2017), integrated cavity output spectroscopy (ICOS) (O'Keefe, 1998), and noise immune cavity enhanced optical heterodyne molecular spectroscopy (NICE-OHMS) (Foltynowicz et al., 2008), have been wildly applied in sub-ppm- and even sub-ppb-level trace-gas detections. The CRDS technique was first introduced by O'Keefe et al. (1988), and many commercial instruments based on CRDS have been developed for various applications but mostly for trace-gas detections and real-time monitoring. Generally, due to the use of highfinesse cavity, the equivalent absorption length of CRDS instruments is thousands to tens of thousands of times longer than that of direct absorption spectroscopy using the samelength sample cell (Romanini, 1997). Therefore the measurement sensitivity of CRDS-based instruments is much improved (more than three orders of magnitude) compared to that of direct absorption spectroscopy measurements. Furthermore, compared with the traditional chemical detection methods, such as gas chromatography (GS) (Loftfield et al., 1997) and mass spectrometry (MS) (De Gouw et al., 2003), CRDS is allowed to take real-time measurements under the premise of high-sensitivity without time-consuming sample preparations. As both high sensitivity and real-time detection are of great significance to environmental monitoring, CRDS is a suitable method for atmospheric trace-gas monitoring. Moreover, CRDS also has the potential for use in exhaled breath tests (Mashir and Dweik, 2009), since the exhaled air contains many biomarker trace gases (for example $\mathrm{CH}_{4}, \mathrm{NO}, \mathrm{N}_{2} \mathrm{O}$, and $\mathrm{NH}_{3}$; De Lacy Costello et al., 2013, Brubaker, 2016, Bleakley and Tiedje, 1982, and Kearney et al., 2002) that reflect some physiological processes and/or diseases in human body. However, mid-infrared (midIR) CRDSs for trace-gas detections were rarely reported in the early days because of the unavailability of mid-IR laser sources. Mid-IR light sources based on nonlinear optical techniques, such as quasi-phase matching difference frequency generation (QPM-DFG) (Petrov et al., 1996), had output power that was too low, e.g., $16 \mu \mathrm{W}$ (Whittaker et al., 2012), to have practical applications. In recent years, with the rapid development of advanced tunable high-power midinfrared sources, especially external-cavity quantum cascade lasers (EC-QCL) (Botez et al., 2018), the LODs of CRDS for trace-gas detections have been greatly improved. For example, Maity et al. (2017) achieved an LOD of $52 \mathrm{pptv}$ for $\mathrm{CH}_{4}$ at $7.5 \mu \mathrm{m}$, Banik et al. (2017) achieved an LOD of $5 \mathrm{ppbv}$ for $\mathrm{N}_{2} \mathrm{O}$ at $5.2 \mu \mathrm{m}$, Long et al. (2016) achieved an LOD of 2 pptv for $\mathrm{N}_{2} \mathrm{O}$ at $4.5 \mu \mathrm{m}$, Maithani et al. (2018) achieved an LOD of $740 \mathrm{pptv}$ for $\mathrm{NH}_{3}$ at $6.3 \mu \mathrm{m}$ and Zhou et al. (2018) achieved an LOD of $410 \mathrm{pptv}$ for NO at $5.3 \mu \mathrm{m}$.

In this paper, we developed a trace-gas sensor based on mid-IR CW-CRDS technique with a tunable EC-MHF QCL operating at the spectral range from 1290 to $1350 \mathrm{~cm}^{-1}$ and applied the setup to detect trace $\mathrm{CH}_{4}$ and $\mathrm{N}_{2} \mathrm{O}$ in normal laboratory air and outdoor atmospheric air as well as in exhaled breath. Experimentally it was observed that the measurement results were subject to a temperature fluctuation of about $0.4^{\circ}$ caused by air conditioning for the laboratory room where the measurements were taken. This effect of temperature fluctuation on CRDS measurements was analyzed in detail and corrected via data processing, which resulted in an improvement in the measurement sensitivity of CRDS. With the correction of temperature effect, a measurement sensitivity as low as $7.2 \times 10^{-10} \mathrm{~cm}^{-1}$ absorption coefficient was experimentally achieved. To achieve high measurement sensitivity, as well as high reliability for separate and simultaneous detections of trace $\mathrm{CH}_{4}$ and $\mathrm{N}_{2} \mathrm{O}$ in atmospheric air under normal atmospheric pressure, four wave number bands within the spectral range of the QCL were selected for the reliable concentration determinations of $\mathrm{CH}_{4}$ and $\mathrm{N}_{2} \mathrm{O}$, with one band for separate $\mathrm{N}_{2} \mathrm{O}$ detection, two bands for separate $\mathrm{CH}_{4}$ detection, and one band for simultaneous $\mathrm{CH}_{4}$ and $\mathrm{N}_{2} \mathrm{O}$ detections. The $\mathrm{CH}_{4}$ and $\mathrm{N}_{2} \mathrm{O}$ concentrations determined from the four bands were in good agreement, indicating the reliability of the measurement results. Finally, the developed CRDS experimental setup was used to measure the concentrations of $\mathrm{CH}_{4}$ and $\mathrm{N}_{2} \mathrm{O}$ collected at different locations, as well as one collected exhaled breath, and to simultaneously monitor $\mathrm{CH}_{4}$ and $\mathrm{N}_{2} \mathrm{O}$ concentrations of indoor laboratory air continuously for over $45 \mathrm{~h}$, demonstrating the applicability of CRDS for sensitive environmental monitoring and exhaled breath analysis.

\section{Experimental setup}

The CRDS experimental setup is schematically depicted in Fig. 1. A tunable mid-IR external-cavity CW-MHF QCL (41074-MHF, Daylight Solutions) is used as the optical source, which continuously outputs a collimated laser beam with a narrow linewidth $\left(<30 \mathrm{MHz}\right.$ or $\left.0.001 \mathrm{~cm}^{-1}\right)$ and a relatively high power $(\sim 160 \mathrm{~mW})$ in the spectral range from 1290 to $1350 \mathrm{~cm}^{-1}$. To block the reflection of the laser beam by the ring-down cavity optics from re-entering the QCL resonator and destabilizing the output spectrum and power, an optical isolator with a central wavelength of $7.2 \mu \mathrm{m}$ and isolation ratio of $>30 \mathrm{~dB}$ (FIO-5-7.2, Innpho) is placed in front of the laser output port. Subsequently, the QCL beam propagates through an acousto-optic modulator (AOM, acting as a fast optical switch) (I-M041, Gooch \& Housego) controlled by a homemade high-speed (with response time $<50 \mathrm{~ns}$ ) threshold trigger, and the first-order beam outputted from the AOM is coupled into the ring-down cavity (the sample cell) consisting of a $50 \mathrm{~cm}$ long stainless steel tube (CRD Optics). A pair of high-reflectivity (reflectivity $>99.98 \%$; CRD Optics) plane-concave mirrors with diameter of 1 inch and radius of curvature of $-1 \mathrm{~m}$ are installed at both ends of the sample cell via two three-dimensionally adjustable optical mounts which are mounted to the sample cell by screws. A He-Ne laser at $632.8 \mathrm{~nm}$ is employed to help align the high-reflectivity cavity mirrors. The QCL beam that 


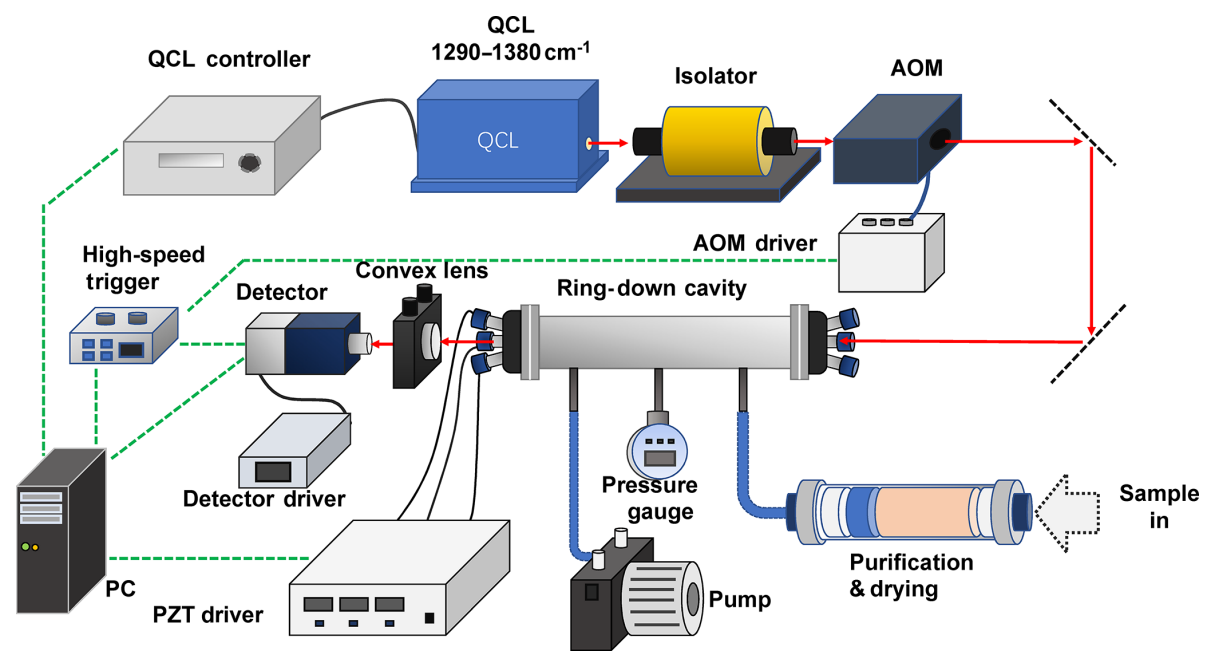

Figure 1. Schematic diagram of the CRDS experimental setup.

transmitted through the sample cell is focused by a focusing lens, placed closely behind the rear cavity mirror, into

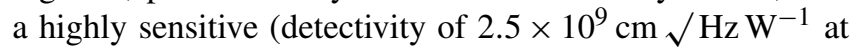
$8 \mu \mathrm{m})$, TE-cooled, high-speed HgCdTe infrared photovoltaic detector (PVMI-4TE-8, Vigo, Poland). Then the detected CRD signal is recorded by a data acquisition (DAQ) card (M2i.3010, Spectrum Instrumentation, Germany) and processed by a MATLAB program in real time. The QCL is tuned by the laser controller (via synchronously adjusting the tuning grating and the length of the laser cavity) with a step of $0.01 \mathrm{~cm}^{-1}$ (with accuracy $<0.003 \mathrm{~cm}^{-1}$ ). As the free spectral range (FSR, $300 \mathrm{MHz}$ or $0.01 \mathrm{~cm}^{-1}$ ) of the ringdown cavity (RDC) is much larger than the laser linewidth $\left(<0.001 \mathrm{~cm}^{-1}\right)$, at each step the RDC length is modulated via three piezoelectric transducers (PZT, Model PE-4, Thorlabs) attached to the optical mount when installing the rear high-reflectivity cavity mirror. The PZTs are synchronously driven by a triangular wave function generated by a threechannel open-loop PZT driver (MDT694B, Thorlabs) to periodically modulate the RDC length over one half of the wavelength, about $4 \mu \mathrm{m}$, for the coupling of QCL laser power into the RDC via resonance of the laser spectral line with one RDC mode. Within one cavity length modulation period, laser power with a TEM 00 mode (RDC mode) builds up inside the RDC. Correspondingly, the beam power transmitted through the RDC and detected by the infrared detector also increases rapidly. At the same time that the detected signal amplitude exceeds a preset voltage threshold $(20-2000 \mathrm{mV})$, the threshold trigger sends out a triggering signal to shut down the AOM and a ring-down signal sequence is recorded by the DAQ and processed by a personal computer (PC). A vacuum pump (nominal ultimate pressure $<8$ mbar, MPC 301Z, Welch) and a pressure gauge (nominal pressure accuracy \pm 0.5 mbar, LEX1, Keller) are connected to the sample cell to control the pressure of the gas mixture under test and to replace the gas mixture inside the sample cell when necessary. During the laser spectral tuning, at each step the frequency is determined by the RDC mode in resonance with the laser line. The maximum frequency error should be $<0.01 \mathrm{~cm}^{-1}$ (determined by the FSR of RDC and the scan step), as the frequency at each RDC mode is not accurately controlled.

A fitting program based on the Levenberg-Marquardt algorithm is applied to fit the recorded ring-down signal to an exponential decay function to determine the ring-down time $\tau$. By tuning the QCL wavelength, the dependence of ring-down time on wavelength over the required spectral range is obtained. The wavelength-dependent absorption coefficient $\alpha$ of the gas sample within the sample cell is determined from the measured ring-downtime $\tau$ using equation $\alpha(\lambda)=\frac{1}{c}\left(\frac{1}{\tau}-\frac{1}{\tau_{0}}\right)$, where $c$ is the speed of light, $\lambda$ is the laser wavelength, and $\tau_{0}$ is the ring-down time of an "empty" cavity (without absorbing sample inside the sample cell).

Since in normal atmospheric air the concentration of water vapor is in the range from $100 \mathrm{ppm}$ up to $4 \%$ and water vapor has strong absorption lines, no CRDS signals can be experimentally observed in the selected spectral range from 1290 to $1350 \mathrm{~cm}^{-1}$. Before measurement, the water vapor in the gas mixture under test has to be mostly removed to a very low level $(<10 \mathrm{ppm})$, which has a negligible influence on the $\mathrm{CH}_{4}$ and $\mathrm{N}_{2} \mathrm{O}$ measurements. In our experiment, a 3A molecular sieve (HuShi Ltd., China), which only allows molecules with dynamic diameter less than $0.3 \mathrm{~nm}$ (Ruthven, 1984) to be adsorbed on it, such as water vapor and ammonia, is employed as the desiccants to eliminate the water vapor in the gas mixture. A filter tube which serves as the gas inlet of the sample cell and is filled up with such desiccants and quartz cotton is connected to the sample cell for purification and drying of the gas sample. In addition, a cage with the same desiccants is put inside the sample cell to absorb the 
water vapor that leaked in, therefore keeping the sample cell nearly water vapor free. With these means of water vapor removal, the residual water vapor in the sample cell is below 1 ppmv and can stay below 1 ppmv for several months after one desiccant filling. With this drying method this CRDS experimental setup is capable of analyzing both canned dry gas mixture and untreated atmospheric air with a moderate water vapor concentration. Experimental results demonstrate the effectiveness of this drying process as no absorption lines of water vapor are observed in the measured spectra. On the other hand, a spectral line of $1312.5 \mathrm{~cm}^{-1}$ of the water vapor, as presented in Section B (not shown), can be used to monitor or even simultaneously determine the water vapor concentration (below $100 \mathrm{ppmv}$ ) if necessary.

The gas mixtures used in the experiment are ambient air collected at different locations within the university campus in the central city area of Chengdu, China in the same period of time (15:00-17:00 on 13 June 2018), $3 \mathrm{~h}$ after light rain. One sample is the air from the laboratory room (A), one is from an outdoor parking lot outside the laboratory building (B), and one is from a wetland on the campus (C). The exhaled breath (D) of one healthy male person is also collected in the laboratory room (same as A) for measurement. Indoor laboratory air is also continuously measured over $45 \mathrm{~h}$ (from 6 to 8 November 2018). In our experiment, the exhaled air is collected with a $3 \mathrm{~L}$ sampling bag, which can be fully filled with only one deep exhalation from a participant. The filled sampling bag is then connected to the sample cell via a valve. The sample cell is first vacuumed by the vacuum pump and then filled with the exhaled air by opening the valve. This procedure is repeated two times for a complete replacement of gas in the sample cell by the exhaled air. As the volume of the sample cell is around $0.5 \mathrm{~L}$, the exhaled air of the $3 \mathrm{~L}$ sampling bag is sufficient for the exhaled air measurement. A similar procedure for outdoor open air collection is followed.

\section{Results and discussions}

\subsection{Limit of detection with and without temperature fluctuation correction}

For sensitive trace-gas detections, the sensitivity limit of the CRDS experimental setup is first tested with an empty cavity. In our case, the empty cavity is filled with normal laboratory air with a reduced pressure of $6.4 \mathrm{mbar}$ (the lowest pressure reached by the vacuum pump) and measured at an absorption-free wave number $\left(1330.50 \mathrm{~cm}^{-1}\right)$. Figure $2 \mathrm{a}$ presents the recorded ring-down time of the empty cavity over $4400 \mathrm{~s}$ and corresponding fast Fourier transform (FFT) spectrum of the ring-down time sequence. To improve the measurement sensitivity, in general the CRDS signal is averaged to enhance the signal-to-noise ratio (SNR) of the measurements and an optimal averaging number is determined by Allan variance. Figure 3 shows the calculated Allan vari- ance vs. averaging number for the recorded empty ring-down time. The optimal averaging number is determined to be 151 , corresponding to $22.5 \mathrm{~s}$ averaging time. With the optimal averaging number, the average empty ring-down time $\left(\tau_{0}\right)$ is $13.1 \mu$ s with a standard deviation $(1 \sigma)$ of $4.2 \times 10^{-3} \mu$ s, which is translated to a minimum absorption coefficient $\left(\alpha_{\min }\right)$ of $8.1 \times 10^{-10} \mathrm{~cm}^{-1}$. From Fig. 2a, periodical fluctuations of the ring-down time are observed, as clearly indicated in the lowfrequency end of the corresponding FFT spectrum. To investigate the sources for these low-frequency periodical fluctuations, the temperature in the laboratory room is recorded simultaneously and the results are presented in Fig. 2b. The temperature also shows periodical fluctuations with frequencies of the periodical fluctuations of the ring-down time, as demonstrated by the FFT spectrum of the temperature. The results presented in Fig. 2a and b clearly indicate that there is a positive correlation between the periodical fluctuations of the ring-down time and temperature in the low-frequency end. That is, the low-frequency periodical fluctuation of the measured ring-down time is partially caused by the temperature fluctuation in the laboratory room.

A detailed investigation reveals that the correlation of ringdown time to temperature fluctuation is mainly caused by the different temperature dependence of the response of the three PZTs as well as the sensitivity of the ring-down time to the misalignment of the cavity mirrors. To test the sensitivity of the ring-down time to the alignment of the cavity mirrors, we first align the cavity mirrors to optimal positions, then apply an offset voltage to each PZT (while no offset voltage is applied to the other two PZTs) and observe how the measured ring-down time is influenced by the applied offset voltage. The results are presented in Fig. 4. An approximately linear relationship between the ring-down time and the applied offset voltage exists for each PZT, and the slopes of such linear dependences for different PZTs are different. This phenomenon is attributed to the difference in the creep and thermal-drift characteristics of PZTs. Normally, PZT is a nonlinear component and no two PZTs' characteristics are identical (Jaffe et al., 1971). Moreover, in our experiment the PZTs are controlled in an open-loop mode. Due to the different temperature sensitivities of the responses of each PZT, temperature fluctuation causes misalignment of the cavity mirrors, which further results in a fluctuation in measured ring-down time, as presented in Fig. 2a. Other thermal effects, such as the cavity length fluctuation and reflectivity fluctuation caused by temperature fluctuation, are negligible compared to cavity alignment fluctuation. It is worth mentioning that experimental observation shows that when the same offset voltage is synchronously applied to all three PZTs, the measured ring-down time is approximately independent from the voltage. This is the case when CRDS measurements are taken.

To eliminate the effect of temperature fluctuation on tracegas detection with CRDS, those frequency components in the FFT spectrum of ring-down time also presented in the 


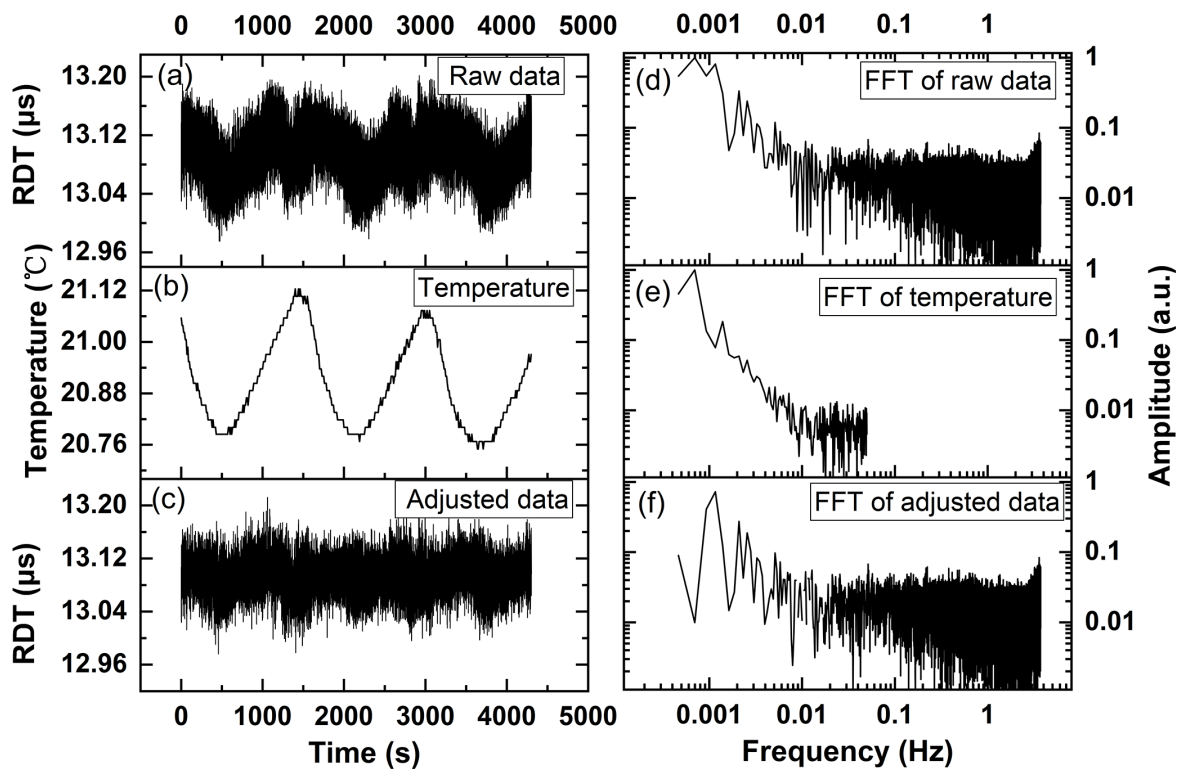

Figure 2. (a) The "empty" ring-down time sequence recorded over $1 \mathrm{~h}$ and (d) corresponding FFT spectrum. (b) The synchronously recorded temperature in the laboratory room and (e) corresponding FFT spectrum. (c) The empty ring-down time sequence after the temperature effect is eliminated with the subtracting method and (f) corresponding FFT spectrum and. RDT represents the ring-down time.

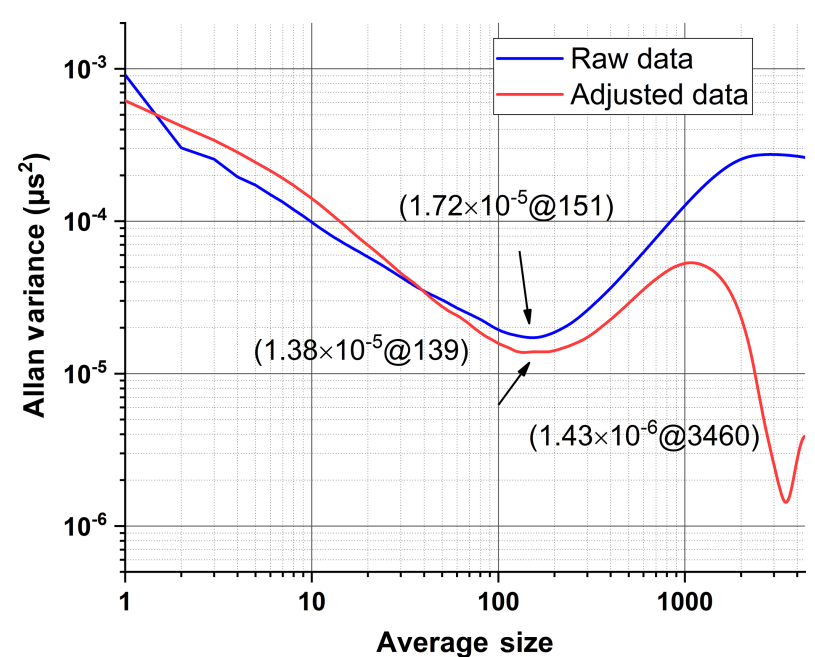

Figure 3. Allan variance plot of raw and adjusted data (with and without temperature effect correction).

FFT spectrum of the temperature fluctuation are subtracted mathematically and the ring-down time sequence is adjusted accordingly, as presented in Fig. 2c. The subtraction is performed with both FFT spectra normalized to the frequency component with the maximum amplitude, which appears at the main frequency of the temperature fluctuation. This subtraction method is reasonable as at the main frequency of the temperature fluctuation, the contributions of other factors to the fluctuation of the ring-down time are negligible compared to that of the temperature fluctuation. After the effect of tem-

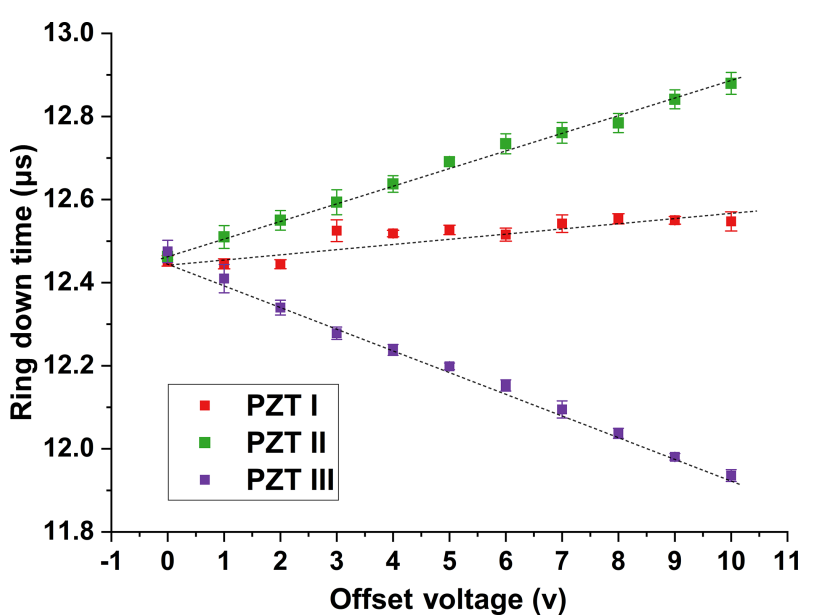

Figure 4. Linear relationship between the offset voltage on each PZT and the measured ring-down time.

perature fluctuation on the ring-down time measurement is eliminated, the absorption coefficient sensitivity limit $\alpha_{\text {min }}$ is first improved to $7.2 \times 10^{-10} \mathrm{~cm}^{-1}$, with the optimal averaging number changes to 139 , corresponding to $21 \mathrm{~s}$ averaging time, as presented in Fig. 3. Figure 3 also shows that there is a second minimum Allan variance if the averaging time is further increased, indicating $\alpha_{\min }$ can be further improved to $2.3 \times 10^{-10} \mathrm{~cm}^{-1}$ with optimal averaging number of 3460 and corresponding averaging time of $519 \mathrm{~s}$. The results demonstrate that with a temperature effect correction the measurement sensitivity could be greatly improved by 


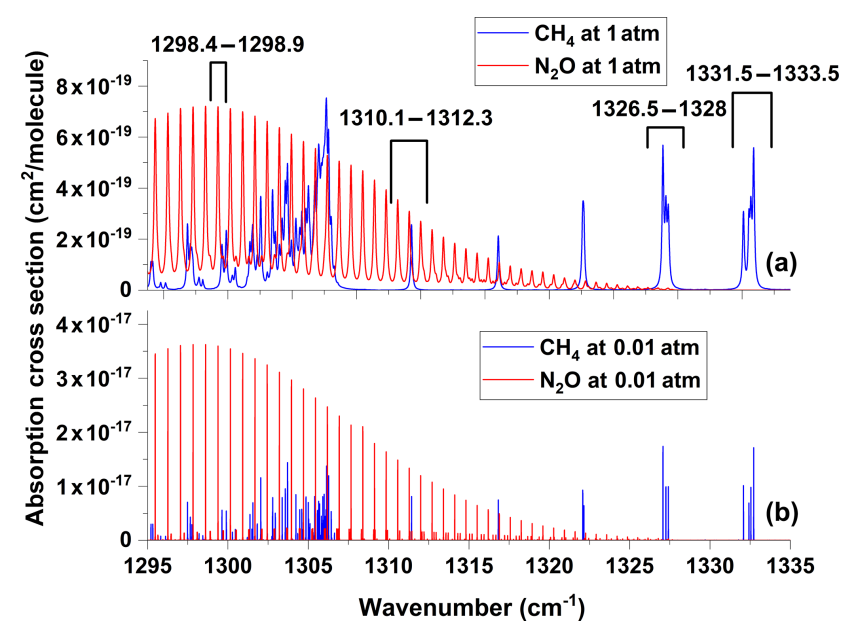

Figure 5. HITRAN spectra of $\mathrm{N}_{2} \mathrm{O}$ and $\mathrm{CH}_{4}$ in the spectral range from 1295 to $1335 \mathrm{~cm}^{-1}$ at (a) 1 and (b) $0.01 \mathrm{~atm}$.

increasing the measurement time as a compromise (519s vs. $22.5 \mathrm{~s})$.

For real trace-gas detections, the sensitivity limit achieved above with the empty cavity may not be fulfilled due to the presence of absorbing sample in the cavity and other effects such as laser wavelength fluctuation and a limited wavelength tuning step for spectral measurement. To find out the limits of detection (LODs) of $\mathrm{CH}_{4}$ and $\mathrm{N}_{2} \mathrm{O}$ with the CRDS experimental setup, the sample cell is filled with ambient air at $1 \mathrm{~atm}$ and the ring-down data is recorded continuously at peaks of the absorption lines of $\mathrm{N}_{2} \mathrm{O}\left(1298.60 \mathrm{~cm}^{-1}\right)$ and $\mathrm{CH}_{4}\left(1327.07 \mathrm{~cm}^{-1}\right)$, and the corresponding Allan variances are calculated. The achieved minimum $\sigma_{\text {Allan }}$ values are $3.1 \times 10^{-9} \mathrm{~cm}^{-1}$ at $1327.07 \mathrm{~cm}^{-1}$ for $\mathrm{CH}_{4}$, and $2.8 \times$ $10^{-9} \mathrm{~cm}^{-1}$ at $1298.60 \mathrm{~cm}^{-1}$ for $\mathrm{N}_{2} \mathrm{O}$, which correspond to LODs of 22 pptv for $\mathrm{CH}_{4}$ and 16 pptv for $\mathrm{N}_{2} \mathrm{O}$. These LODs are obtained with approximately $15 \mathrm{~s}$ of averaging time. The achieved LODs are lower than those achieved by other groups employing CRDS for $\mathrm{CH}_{4}$ and $\mathrm{N}_{2} \mathrm{O}$ detections in recent years, as described in Sect. 1.

The LODs for $\mathrm{CH}_{4}$ and $\mathrm{N}_{2} \mathrm{O}$ detections can be improved by eliminating the effect of temperature fluctuation via the process presented above. Again, two Allan variance minima are present in the dependence of Allan variance on averaging time after the temperature effect is corrected. The corresponding LODs for $\mathrm{CH}_{4}$ and $\mathrm{N}_{2} \mathrm{O}$ detections are 13 and $11 \mathrm{pptv}$ with 10.4 and $10.2 \mathrm{~s}$ averaging times for the first minimum and 5 and 9 pptv with 482.5 and $311 \mathrm{~s}$ averaging times for the second minimum. Such low LODs allow sensitive detections of $\mathrm{CH}_{4}$ and $\mathrm{N}_{2} \mathrm{O}$ with sub-ppbv-level concentrations.

\subsection{Detection of $\mathrm{CH}_{4}$ and $\mathrm{N}_{2} \mathrm{O}$ in ambient and exhaled breath air}

For simultaneous detections of $\mathrm{CH}_{4}$ and $\mathrm{N}_{2} \mathrm{O}$ in real applications, the optimal absorption lines or spectral ranges have to be carefully selected. For the spectral range from 1290 to $1350 \mathrm{~cm}^{-1}, \mathrm{~N}_{2} \mathrm{O}$ and $\mathrm{CH}_{4}$ both have strong absorption lines. Figure 5 shows the spectral lines of $\mathrm{N}_{2} \mathrm{O}$ and $\mathrm{CH}_{4}$ in the spectral range from 1295 to $1335 \mathrm{~cm}^{-1}$ at 1 and $0.01 \mathrm{~atm}$. (The spectral data are from HITRAN 2016). When the pressure in the sample cell is reduced, individual absorption lines are well separated and can be fitted independently. At $1 \mathrm{~atm}$, on the other hand, absorption lines are mixed and partially overlapped, especially when $\mathrm{CH}_{4}$ and $\mathrm{N}_{2} \mathrm{O}$ are both presented. In this case, care has to be taken to select the appropriate spectral band(s) for separate or simultaneous detections of $\mathrm{CH}_{4}$ and $\mathrm{N}_{2} \mathrm{O}$. In our experiment, four spectral sections in the spectral range from 1295 to $1335 \mathrm{~cm}^{-1}$ are tested for the detection of $\mathrm{CH}_{4}$ and $\mathrm{N}_{2} \mathrm{O}$. The selected spectral sections are listed in Table 1. That is, Section A contains one $\mathrm{N}_{2} \mathrm{O}$ absorption line that is slightly weaker than the strongest $\mathrm{N}_{2} \mathrm{O}$ absorption line $\left(1297.8315 \mathrm{~cm}^{-1}\right.$, $\left.1.689 \times 10^{-19} \mathrm{~cm}^{-1}\left(\text { molec cm }{ }^{-2}\right)^{-1}\right)$ but is well separated from the adjacent absorption lines of $\mathrm{CH}_{4}$ and $\mathrm{N}_{2} \mathrm{O}$. Section $\mathrm{B}$ contains three $\mathrm{N}_{2} \mathrm{O}$ lines and one $\mathrm{CH}_{4}$ line. These four absorption lines are sufficiently strong and well separated. Sections $\mathrm{C}$ and $\mathrm{D}$ contain combinations of three and four overlapped absorption lines of $\mathrm{CH}_{4}$ which are well separated from the absorption lines of $\mathrm{N}_{2} \mathrm{O}$ in the measurable spectral range. Section $\mathrm{A}$ is used for independent $\mathrm{N}_{2} \mathrm{O}$ detection, while sections $\mathrm{C}$ and $\mathrm{D}$ are used for independent $\mathrm{CH}_{4}$ detection, and Section B is for simultaneous $\mathrm{CH}_{4}$ and $\mathrm{N}_{2} \mathrm{O}$ detections.

Figure 6 shows the measured spectral lines, corresponding best fits, and fit residuals for the ambient air collected in the laboratory room. The measured data are the average of 128 measurements and took approximately $5 \mathrm{~s}$ for each wave number point. When performing the spectral fitting, the spectral profile is assumed to be Voigt, and the laser frequency is linearly shifted to match the spectral lines of the target gas. From Section A, the $\mathrm{N}_{2} \mathrm{O}$ concentration is determined to $0.224 \pm 0.002$ ppmv. From sections $\mathrm{C}$ and $\mathrm{D}$, the $\mathrm{CH}_{4}$ concentrations are determined to $1.698 \pm 0.002$ and $1.697 \pm 0.002 \mathrm{ppmv}$, respectively, while from Section B, the $\mathrm{CH}_{4}$ and $\mathrm{N}_{2} \mathrm{O}$ concentrations are determined to $1.700 \pm 0.002$ and $0.222 \pm 0.002$ ppmv. The $2 \mathrm{ppbv}$ concentration uncertainties represent the standard deviation of six repeat measurements. The small differences among the concentration values determined from different sections are mainly due to the misalignment caused by a small AOM-induced change in the deflection angle of the diffracting laser beam when tuning the laser wave number. As the RDC is aligned at $1310 \mathrm{~cm}^{-1}$, in principle the concentrations obtained from Section B are mostly close to the true values. Overall the $\mathrm{CH}_{4}$ and $\mathrm{N}_{2} \mathrm{O}$ concentrations determined from different sec- 
Table 1. Selected spectral sections for simultaneous measurements of $\mathrm{CH}_{4}$ and $\mathrm{N}_{2} \mathrm{O}$ in air.

\begin{tabular}{|c|c|c|c|}
\hline $\begin{array}{l}\text { Spectral } \\
\text { section }\end{array}$ & $\begin{array}{l}\text { Spectral range } \\
\mathrm{cm}^{-1}\end{array}$ & $\begin{array}{l}\mathrm{CH}_{4} \text { absorption line/intensity } \\
\mathrm{cm}^{-1} / \mathrm{cm}^{-1}\left(\text { molec } \mathrm{cm}^{-2}\right)^{-1}\end{array}$ & $\begin{array}{l}\mathrm{N}_{2} \mathrm{O} \text { absorption line/intensity } \\
\mathrm{cm}^{-1} / \mathrm{cm}^{-1}\left(\text { molec } \mathrm{cm}^{-2}\right)^{-1}\end{array}$ \\
\hline A & $1298.4-1298.9$ & - & $1298.6031 / 1.681 \times 10^{-19}$ \\
\hline B & $1310.1-1312.3$ & $\begin{array}{r}1311.431 / 4.447 \times 10^{-20} \\
1311.2841 / 6.008 \times 10^{-20} \\
1311.9973 / 5.403 \times 10^{-20}\end{array}$ & $1310.5673 / 6.693 \times 10^{-20}$ \\
\hline $\mathrm{C}$ & $1326.5-1328$ & $\begin{array}{r}1327.074 / 9.694 \times 10^{-20} \\
1327.257 / 5.816 \times 10^{-20} \\
1327.410 / 5.82 \times 10^{-20}\end{array}$ & - \\
\hline $\mathrm{D}$ & $1331.5-1333$ & $\begin{array}{l}1332.085 / 5.766 \times 10^{-20} \\
1332.425 / 3.843 \times 10^{-20} \\
1332.547 / 5.768 \times 10^{-20} \\
1332.721 / 9.624 \times 10^{-20}\end{array}$ & - \\
\hline
\end{tabular}

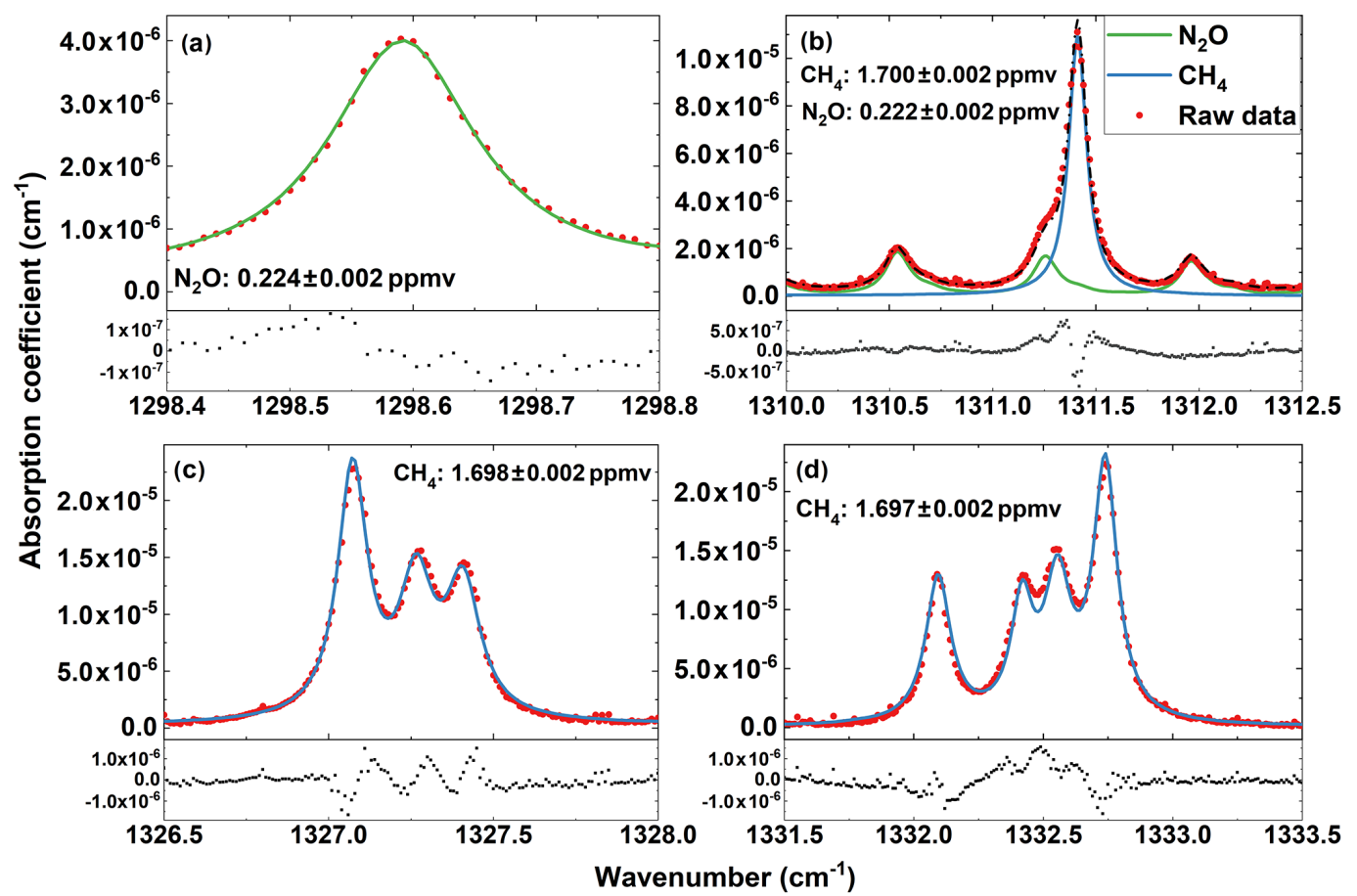

Figure 6. Measured spectra (circles), corresponding best fits (solid lines), and fit residuals (lower figures) for four selected spectral bands at (a) $1298.3-1299.1 \mathrm{~cm}^{-1}$, (b) $1310.1-1312.3 \mathrm{~cm}^{-1}$, (c) $1326.5-1328 \mathrm{~cm}^{-1}$, and (d) $1331.5-1333.5 \mathrm{~cm}^{-1}$.

tions are very consistent, indicating the reliability of the measurement results. The good agreements between the $\mathrm{CH}_{4}$ and $\mathrm{N}_{2} \mathrm{O}$ concentrations determined separately (from sections A, $\mathrm{C}$, and D) and simultaneously (from Section B) demonstrate that $\mathrm{CH}_{4}$ and $\mathrm{N}_{2} \mathrm{O}$ concentrations can be simultaneously determined by employing a narrow band containing absorption lines of both gases for spectral measurements, therefore shortening the measurement time.
The concentration uncertainties can also be estimated from the fit residuals presented in Fig. 6. The estimated uncertainties for $\mathrm{N}_{2} \mathrm{O}$ concentration are 4 ppbv from Section A and $13 \mathrm{ppbv}$ from Section $\mathrm{B}$, and for $\mathrm{CH}_{4}$ concentration they are 19 ppbv from Section B, 19 ppbv from Section C, and $18 \mathrm{ppbv}$ from Section $\mathrm{D}$. These values are higher than the $2 \mathrm{ppbv}$ determined from repeat measurements due to the large fit residuals that appeared around the absorption peaks, which are caused by uncertainties in wavelength, HI- 


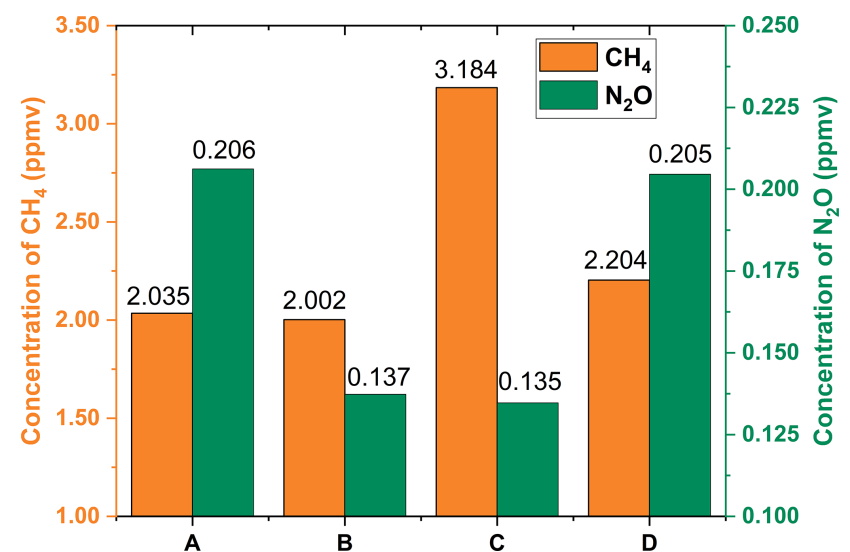

Figure 7. Measured $\mathrm{CH}_{4}$ and $\mathrm{N}_{2} \mathrm{O}$ concentrations in ambient air collected at different locations (a, b, c) and in exhaled breath (d). (a) Laboratory room, (b) parking lot, (c) wetland, and (d) exhaled breath of one healthy person collected in the laboratory room.

TRAN spectral line intensity, line mixing (Gordon et al., 2017), pressure, temperature, etc. Our calculations indicate that the wavelength uncertainty and HITRAN spectral line intensity error are the major sources for the large residuals around the absorption peaks. From the residuals departing from the peaks the estimated uncertainties for $\mathrm{N}_{2} \mathrm{O}$ concentration become 2 ppbv from Section A and 4 ppbv from Section $\mathrm{B}$, and for $\mathrm{CH}_{4}$ concentration they are $3 \mathrm{ppbv}$ from Section B, 4 ppbv from Section C, and 4 ppbv from Section $\mathrm{D}$. These uncertainty values become comparable to the 2 ppbv determined from repeat measurements. As in principle CRDS measures the absolute absorption, the concentration uncertainties obtained from the spectral fit residuals represent the absolute accuracy for the concentration determination, the uncertainties obtained from the repeat spectral measurements represent the relative accuracy, and the uncertainties obtained from Allan variances of repeat measurements at fixed wavelengths represent the measurement sensitivity. From these analyses we estimate the measurement sensitivity, relative accuracy, and absolute accuracy of our experimental setup for $\mathrm{CH}_{4}$ and $\mathrm{N}_{2} \mathrm{O}$ detections in the air are around 10-20 pptv, 2, and $20 \mathrm{ppbv}$. The absolute accuracy could be improved to be comparable to the relative accuracy by calibrating the measurement with standard "known" sample of ppb-level concentration and controlling accurately the laser frequency during the spectral measurements (Maity et al. 2017; Maithani et al., 2018).

It is worth mentioning that, for the measurements presented in Fig. 6, the effect of temperature fluctuation is not eliminated due to the relatively high concentration values compared to the LODs as well as the relatively short measurement time. Still, the temperature-fluctuation-caused uncertainty of $\mathrm{CH}_{4}$ and $\mathrm{N}_{2} \mathrm{O}$ concentration is presented in the determined concentration values and can be corrected if nec-

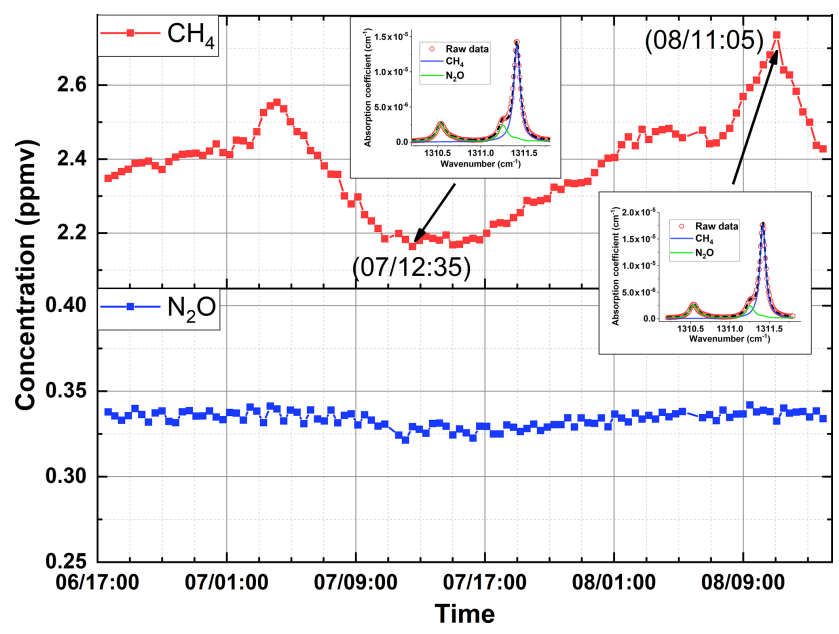

Figure 8. Measured $\mathrm{CH}_{4}$ and $\mathrm{N}_{2} \mathrm{O}$ concentrations in laboratory room (Location A) for a period of $45.5 \mathrm{~h}$ from 17:00 on 6 November to $14: 30$ on 8 November 2018 . Insets show the measured absorption spectra at two different time series and corresponding best fits for the determination of $\mathrm{CH}_{4}$ and $\mathrm{N}_{2} \mathrm{O}$ concentrations.

essary, though this uncertainty is small and negligible in our case.

The CRDS experimental setup is then used to measure the $\mathrm{CH}_{4}$ and $\mathrm{N}_{2} \mathrm{O}$ concentrations in ambient air collected at different locations and in the exhaled breath of one healthy person under $1 \mathrm{~atm}$. The results are presented in Fig. 7 and show that (1) the $\mathrm{N}_{2} \mathrm{O}$ concentration in the indoor air of the laboratory room is higher than that of open outdoor areas (parking lot and wetland) ( 0.206 ppmv vs. $0.135-0.137 \mathrm{ppmv})$; (2) the $\mathrm{CH}_{4}$ concentration of outdoor air collected in a wetland is higher than that collected in a parking lot $(3.184 \mathrm{ppmv}$ vs. 2.002 ppmv), while the $\mathrm{N}_{2} \mathrm{O}$ concentration is little changed $(0.135$ ppmv vs. $0.137 \mathrm{ppmv})$. This observation might be attributed to the release of $\mathrm{CH}_{4}$ from the anaerobic bacteria in the water and soil of wetlands (Cao et al., 1998). (3) The $\mathrm{CH}_{4}$ concentration of exhaled breath is approximately $169 \mathrm{ppbv}$ higher than the environmental air (2.204 ppmv vs. 2.035 ppmv in the laboratory room), while the change in $\mathrm{N}_{2} \mathrm{O}$ concentration is not significant $(0.205$ ppmv vs. $0.206 \mathrm{ppmv})$. The slight variance in $\mathrm{CH}_{4}$ concentration demonstrates the physiological process of $\mathrm{CH}_{4}$ in the human body. The concentration of $\mathrm{CH}_{4}$ is closely related to some anaerobic fermentations, such as $M$. smithii in the human gut (Kim et al., 2012). From these measurements it is found that the measured $\mathrm{N}_{2} \mathrm{O}$ concentration of air samples, which is between $0.206 \mathrm{ppmv}$ and $0.135 \mathrm{ppmv}$, is lower than the reported normal level of open air, about $0.3 \mathrm{ppm}$ (Davidson, 2009). This might be due to the air samples measured in our experiment being collected in a central city area, which is far away from agricultural areas where $\mathrm{N}_{2} \mathrm{O}$ is mainly produced via agricultural practices. 


\subsection{Continuous monitoring of $\mathrm{CH}_{4}$ and $\mathrm{N}_{2} \mathrm{O}$ in ambient air}

Finally, the experimental setup is used to continuously measure the concentrations of $\mathrm{CH}_{4}$ and $\mathrm{N}_{2} \mathrm{O}$ in laboratory air for $45.5 \mathrm{~h}$ from 17:00 on 6 November to 14:30 on 8 November 2018. The results are presented in Fig. 8. The time resolution is $25 \mathrm{~min}$, determined by the tuning stability of the QCL. It is experimentally observed that when the laser is tuned from one wave number to the next wave number with a step of $0.01 \mathrm{~cm}^{-1}$, a time interval of approximately $6 \mathrm{~s}$ is needed to have a stable tuning (without mode hopping). For the results presented in Fig. 8, the spectrum is measured with 170 wave number points in the spectral band B from 1310.10 to $1311.80 \mathrm{~cm}^{-1}$ with a step of $0.01 \mathrm{~cm}^{-1}$. At each wave number the ring-down signals are recorded 150 times in approximately $7 \mathrm{~s}$ to avoid tuning instability. The laboratory air continuously flows in or out of the sample cell at a flow rate of approximately $2 \mathrm{~L} \mathrm{~min}^{-1}$ at normal atmospheric pressure. Slow fluctuations of $\mathrm{CH}_{4}$ and $\mathrm{N}_{2} \mathrm{O}$ concentrations are observed due to regular air exchange (controlled by an air conditioner) between indoor laboratory air and outdoor open air. It is noticed that the measured $\mathrm{N}_{2} \mathrm{O}$ concentrations are higher than those measured on 13 June 2018 and are within the reported normal range of open air, while the measured $\mathrm{CH}_{4}$ concentrations are comparable to those measured on 13 June.

It is worth mentioning that in the measurement results presented in Figs. 7 and 8, the effect of temperature fluctuation is not eliminated, as the measurement sensitivity of CRDS experimental setup without temperature effect correction is sufficiently high that it makes the correction unnecessary, as there will be no quantitative difference between uncorrected and corrected data under our experimental conditions. Still, the idea to eliminate the effect of temperature fluctuation on the trace-gas detection presented in this paper is helpful to situations in which very high sensitivity is required for the detection of trace gases in locations where temperature is not well controlled, for example, in long-term unattended outdoor or open-field monitoring of trace gases in the ppbv to sub-ppbv levels. In open fields the temperature changes greatly during day and night and the effect of temperature fluctuation may become significant. The temperature effect can be eliminated by measuring the temperature dependence of measured concentrations before the CRDS instruments are placed to the open fields. Once the CRDS instruments are in place where temperature is monitored, the temperature effect can be corrected accordingly. It is worth mentioning that the subtracting method described in Sect. 3.1 and used to eliminate the effect of temperature fluctuation is applicable only when the temperature fluctuation is periodic. In principle, the effect of temperature fluctuation can always be eliminated by establishing a quantitative relation between the temperature and the ring-down time, if such a quantitative relation is experimentally repeatable and measurable. In our case, this method is not used as such a quantitative relation is unfortunately very complicated.

\section{Conclusions}

We have developed a highly sensitive trace-gas sensor based on mid-IR CW-CRDS techniques, in which a tunable ECQCL at central wavelength of $\sim 7.6 \mu \mathrm{m}$ was employed to cover several strong absorption lines of $\mathrm{CH}_{4}$ and $\mathrm{N}_{2} \mathrm{O}$. We have observed low-frequency periodical fluctuations of measured ring-down time, and correlated ring-down time fluctuations mainly to temperature fluctuations presented at the test site. It was found that these correlations were attributed to creep and thermal-drift characteristics of PZTs employed to modulate the cavity length for coupling the laser power into the ring-down cavity. By mathematically eliminating the effect of temperature fluctuation, a sensitivity limit of $7.2 \times 10^{-10} \mathrm{~cm}^{-1}$ has been experimentally achieved with $21 \mathrm{~s}$ averaging time and could be further improved to $2.3 \times 10^{-10} \mathrm{~cm}^{-1}$ with $519 \mathrm{~s}$ averaging time. For $\mathrm{CH}_{4}$ and $\mathrm{N}_{2} \mathrm{O}$ absorption lines located at 1298.60 and $1327.07 \mathrm{~cm}^{-1}$, with temperature effect correction detection limits of 13 and $11 \mathrm{pptv}$ were experimentally achieved with 10.4 and $10.2 \mathrm{~s}$ averaging time and could be further improved to 5 and $9 \mathrm{pptv}$ by increasing the averaging time to 482.5 and $311 \mathrm{~s}$. The measurements of $\mathrm{CH}_{4}$ and $\mathrm{N}_{2} \mathrm{O}$ concentrations with different spectral bands have demonstrated that $\mathrm{CH}_{4}$ and $\mathrm{N}_{2} \mathrm{O}$ concentrations could be simultaneously determined at $1 \mathrm{~atm}$ with precision on the order of ppbv level. Finally, this CRDS setup could be easily adapted for the detection of other gases such as $\mathrm{C}_{2} \mathrm{H}_{2}, \mathrm{H}_{2} \mathrm{O}_{2}, \mathrm{H}_{2} \mathrm{~S}, \mathrm{SO}_{2}$ and sulfides with anticipated detection limits at the ppbv or even pptv level.

Data availability. Data are available from the authors upon request.

Author contributions. BL and JT designed the experiments and JT and JW performed the experiments and data processing. JT and BL prepared the manuscript with contributions from all co-authors.

Competing interests. The authors declare that they have no conflict of interest.

Special issue statement. This article is part of the special issue "Advances in cavity-based techniques for measurements of atmospheric aerosol and trace gases". It is not associated with a conference.

Review statement. This paper was edited by Weidong Chen and reviewed by Hu Shuiming, Mélanie Ghysels-Dubois, and one anonymous referee. 


\section{References}

Banik, G. D., Som, S., Maity, A., Pal, M., Maithani, S., Mandal, S., and Pradhan, M.: An EC-QCL based $\mathrm{N}_{2} \mathrm{O}$ sensor at $5.2 \mu \mathrm{m}$ using cavity ring-down spectroscopy for environmental applications, Anal. Methods-UK, 9, 2315-2320, https://doi.org/10.1039/c7ay00482f, 2017.

Bleakley, B. H. and Tiedje, J. M.: Nitrous-oxide production by organisms other than nitrifiers or denitrifiers, Appl. Environ. Microbiol., 44, 1342-1348, 1982.

Botez, D., Kirch, J. D., Boyle, C., Oresick, K. M., Sigler, C., Kim, H., Knipfer, B. B., Ryu, J. H., Lindberg, D., Earles, T., Mawst, L. J., and Flores, Y. V: High-efficiency, high-power mid-infrared quantum cascade lasers, Opt. Mater. Express, 8, 1378-1398, https://doi.org/10.1364/OME.8.001378, 2018.

Boucher, O., Friedlingstein, P., Collins, B., and Shine, K. P.: The indirect global warming potential and global temperature change potential due to methane oxidation, Environ. Res. Lett., 4, 044007, https://doi.org/10.1088/1748-9326/4/4/044007, 2009.

Brubaker, P. H.: Use of exhaled nitric oxide measurements to guide treatment in chronic asthma, J. Cardiopulm. Rehabil. Prev., 36, 140-141, https://doi.org/10.1097/HCR.0000000000000175, 2016.

Cao, M., Gregson, K., and Marshall, S.: Global methane emission from wetlands and its sensitivity to climate change, Atmos. Environ., 32, 3293-3299, https://doi.org/10.1016/S13522310(98)00105-8, 1998.

Davidson, E. A.: The contribution of manure and fertilizer nitrogen to atmospheric nitrous oxide since 1860, Nat. Geosci., 2, 659662, https://doi.org/10.1038/ngeo608, 2009.

De Lacy Costello, B. P. J., Ledochowski, M., and Ratcliffe, N. M.: The importance of methane breath testing: A review, J. Breath Res., 7, 024001, https://doi.org/10.1088/1752-7155/7/2/024001, 2013.

De Gouw, J., Warneke, C., Karl, T., Eerdekens, G., Van der Veen, C., and Fall, R.: Sensitivity and specificity of atmospheric trace gas detection by proton-transfer-reaction mass spectrometry, Int. J. Mass Spectrom., 223, 365-382, https://doi.org/10.1016/S13873806(02)00926-0, 2003.

Foltynowicz, A., Schmidt, F. M., Ma, W., and Axner, O.: Noiseimmune cavity-enhanced optical heterodyne molecular spectroscopy: Current status and future potential, Appl. Phys. B Lasers Opt., 92, 313-326, https://doi.org/10.1007/s00340-0083126-z, 2008.

Gordon, I. E., Rothman, L. S., Hill, C., Kochanov, R. V., Tan, Y., Bernath, P. F., Birk, M., Boudon, V., Campargue, A., Chance, K. V., Drouin, B. J., Flaud, J. M., Gamache, R. R., Hodges, J. T., Jacquemart, D., Perevalov, V. I., Perrin, A., Shine, K. P., Smith, M. A. H., Tennyson, J., Toon, G. C., Tran, H., Tyuterev, V. G., Barbe, A., Császár, A. G., Devi, V. M., Furtenbacher, T., Harrison, J. J., Hartmann, J. M., Jolly, A., Johnson, T. J., Karman, T., Kleiner, I., Kyuberis, A. A., Loos, J., Lyulin, O. M., Massie, S. T., Mikhailenko, S. N., Moazzen-Ahmadi, N., Müller, H. S. P., Naumenko, O. V., Nikitin, A. V., Polyansky, O. L., Rey, M., Rotger, M., Sharpe, S. W., Sung, K., Starikova, E., Tashkun, S. A., Auwera, J. Vander, Wagner, G., Wilzewski, J., Wcisło, P., Yu, S., and Zak, E. J.: The HITRAN2016 molecular spectroscopic database, J. Quant. Spectrosc. Radiat. Transf., 203, 3-69, https://doi.org/10.1016/j.jqsrt.2017.06.038, 2017.
Hartmann, D. L., Tank, A. M. G. K., Rusticucci, M., Alexander, L. V, Brönnimann, S., Charabi, Y. A. R., Dentener, F. J., Dlugokencky, E. J., Easterling, D. R., and Kaplan, A.: Observations: atmosphere and surface, in Climate Change 2013 the Physical Science Basis: Working Group I Contribution to the Fifth Assessment Report of the Intergovernmental Panel on Climate Change, Cambridge University Press, 2013.

Jaffe, B., Cook, W. R. and Jaffe, H.: Piezoelectric ceramics, Academic Press, London, New York, 317 pp., 1971.

Kearney, D. J., Hubbard, T., and Putnam, D.: Breath ammonia measurement in Helicobacter pylori infection, Dig. Dis. Sci., 47, 2523-2530, https://doi.org/10.1023/A:1020568227868, 2002.

Kim, G., Deepinder, F., Morales, W., Hwang, L., Weitsman, S., Chang, C., Gunsalus, R., and Pimentel, M.: Methanobrevibacter smithii is the predominant methanogen in patients with constipation-predominant IBS and methane on breath, Dig. Dis. Sci., 57, 3213-3218, https://doi.org/10.1007/s10620-012-2197$1,2012$.

Loftfield, N., Flessa, H., Augustin, J., and Beese, F.: Automated gas chromatographic system for rapid analysis of the atmospheric trace gases methane, carbon dioxide, and nitrous oxide, J. Environ. Qual., 26, 560, https://doi.org/10.2134/jeq1997.00472425002600020030x, 1997.

Long, D. A., Fleisher, A. J., Liu, Q., and Todges, J. T.: Untrasensitive cavity ring-down spectroscopy in the mid-infrared spectral region, Opt. Lett., 41, 1612-1615, 2016.

Maithani, S., Mandal, S., Maity, A., Pal, M., and Pradhan, M.: Highresolution spectral analysis of ammonia near $6.2 \mu \mathrm{m}$ using a cw EC-QCL coupled with cavity ring-down spectroscopy, Analyst, 143, 2109-2114, https://doi.org/10.1039/C7AN02008B, 2018.

Maity, A., Pal, M., Banik, G. D., Maithani, S., and Pradhan, M.: Cavity ring-down spectroscopy using an EC-QCL operating at $7.5 \mu \mathrm{m}$ for direct monitoring of methane isotopes in air, Laser Phys. Lett., 14, 115701, https://doi.org/10.1088/1612202X/aa8584, 2017.

Mashir, A. and Dweik, R. A.: Exhaled breath analysis: The new interface between medicine and engineering, Adv. Powder Technol., 20, 420-425, https://doi.org/10.1016/j.apt.2009.05.003, 2009.

Mosier, A. R., Kroeze, C., Nevison, C., Oenema, O., and Seitzinger, S.: Closing the global $\mathrm{N}_{2} \mathrm{O}$ budget?: nitrous oxide emissions through the agricultural nitrogen cycle inventory methodology, Nutr. Cycl. Agroecosys., 52, 225-248, https://doi.org/10.1023/A:1009740530221, 1998.

O'Keefe, A., Deacon, D. A. G., and Okeefe, A.: Cavity ringdown optical spectrometer for absorption measurements using pulsed laser sources, Rev. Sci. Instrum., 59, 2544, https://doi.org/10.1063/1.1139895, 1988.

O'Keefe, A.: Integrated cavity output analysis of ultraweak absorption, Chem. Phys. Lett., 293, 331-336, https://doi.org/10.1016/S0009-2614(98)00785-4, 1998.

Petrov, K. P., Goldberg, L., Burns, W. K., Curl, R. F., and Tittel, F. K.: Detection of $\mathrm{CO}$ in air by diodepumped 4.6-micron difference-frequency generation in quasi-phase-matched $\operatorname{LiNbO}(3), \quad$ Opt. Lett., 21, 86-88, https://doi.org/10.1364/ol.21.000086, 1996. 
Rapson, T. D. and Dacres, H.: Analytical techniques for measuring nitrous oxide, TRAC-Trends Anal. Chem., 54, 65-74, https://doi.org/10.1016/j.trac.2013.11.004, 2014.

Romanini, D.: CW cavity ring down spectroscopy, Chem. Phys. Lett., 264, 316-322, https://doi.org/10.1016/S00092614(96)01351-6, 1997.

Ruthven, D. M.: Principles of adsorption and adsorption processes, John Wiley \& Sons, New York, 433 pp., 1984.
Whittaker, K. E., Ciaffoni, L., Hancock, G., Peverall, R., and Ritchie, G. A. D.: A DFG-based cavity ring-down spectrometer for trace gas sensing in the mid-infrared, Appl. Phys. B Lasers Opt., 109, 333-343, https://doi.org/10.1007/s00340-012-5150-2, 2012.

Zhou, S., Han, Y., and Li, B.: Pressure optimization of an ECQCL based cavity ring-down spectroscopy instrument for exhaled NO detection, Appl. Phys. B Lasers Opt., 124, 1-8, https://doi.org/10.1007/s00340-018-6898-9, 2018. 